\title{
Progestogen Profiling Over the Course of Diapause and Resumption of Embryo Development in the European Roe Deer
}

\author{
Vera A. van der Weijden a, Anna-Katharina Hankele a, Anna B. Rüegg a, \\ Marion Schmicke ${ }^{b}$, Karoline Rehm ${ }^{c}$, Laurent Bigler ${ }^{c}$, Susanne E. Ulbrich ${ }^{{ }^{*}}$ \\ ${ }^{a}$ ETH Zurich, Animal Physiology, Institute of Agricultural Sciences, Universitaestrasse 2, 8092 Zurich, Switzerland. \\ ${ }^{b}$ Faculty of Natural Sciences, Institute for Agricultural and Nutritional Sciences, MLU Halle Wittenberg, Germany. \\ ${ }^{c}$ University of Zurich, Department of Chemistry, Winterthurerstrasse 190, 8057 Zurich, Switzerland
}

Received 08 September 2019; Accepted 16 November 2019

\begin{abstract}
Progesterone (P4) plays a pivotal role in maintenance of pregnancy in many mammalian species. Species-specific P4 metabolites have been shown to function as primary acting progestogen and the receptor binding capacity varies between species. The European roe deer (Capreolus capreolus) displays a 4-5 month period of embryonic diapause, which decouples fertilization from implantation. The majority of roe deer have two corpora lutea that secrete P4. No changes in P4 concentrations have been observed during pre-implantation embryo development. As $5 \alpha$-DHP is known to play a major role during pregnancy in elephants and horses, we hypothesized that $5 \alpha$-DHP functions as additional progestogen facilitating embryo reactivation. The profile of 11 progestogens was quantified in roe deer plasma over the course of diapause and resumption of embryo development including P4, $3 \alpha$ - and $3 \beta$-DHP, $20 \alpha$ - and $20 \beta$-DHP, $5 \alpha$ - and 5 $\beta$-DHP, $3 \alpha, 5 \alpha$ - and $3 \alpha, 5 \beta$ THP, as well as $3 \beta, 5 \alpha$ - and $3 \beta, 5 \beta$-THP. While P4 was most abundant during diapause and resumption of development, $20 \alpha-$ DHP was the most abundant P4 metabolite. This is different than in pregnant elephants, where $5 \alpha$-DHP was most abundant, and the luteal phase in cattle, where $3 \alpha, 5 \alpha$-THP was most abundant. With the exception of a weak correlation of $3 \beta, 5 \alpha-$ THP, none of the progestogens significantly correlated with embryonic development in the roe deer. Thus, plasma $5 \alpha$-DHP does not seem to play a role in embryo reactivation. We propose that progestogens might contribute to priming the endometrium for supporting embryo development and preparation for implantation.
\end{abstract}

Keywords: Progestogens; Diapause; Roe Deer; LC-MS.

\section{Introduction}

Steroid hormones play an essential role during the estrus cycle and pregnancy. From early embryonic development onwards and throughout maintenance of pregnancy, steroid hormones provide continuous, adequate support for the developing offspring. In cattle, the follicular phase lasts for 4-6 days and is characterized by the development of large follicles. These large follicles contribute to the increase in peripheral pre-ovulatory estradiol-17 (E2) concentrations and induce the pre-ovulatory luteinizing hormone (LH) surge [1]. Upon ovulation, the newly formed corpus luteum (CL) reaches its maximal diameter about a week after ovulation. The peripheral progesterone (P4) concentration is significantly correlated with the luteal mass [2]. In case of pregnancy, the CL provides continuous support of pregnancy either solely as in cattle, pig or goat, or together with the placenta as observed in sheep and horses [3].

Unlike other ruminants where the embryo implants within the first 20 days after fertilization, the European roe deer (Capreolus capreolus) displays a prolonged period of preimplantation development, referred to as embryonic diapause

* Corresponding author: susanne.ulbrich@usys.ethz.ch

$>$ This is an open access article under the CC-BY license (https://creativecommons.org/licenses/by/4.0/).

(C) Authors retain all copyrights. 
[4]. This phenomenon decouples fertilization from subsequent implantation by 4-5 months [4]. Bucks provide functional semen from June to August, and rut, copulation and fertilization take place between the end of July and end of August [4]. After 4-5 months of diapause, embryo development is resumed in late December. Thereupon, the development of the roe deer embryo resembles that of other ruminants [4, 5], namely elongation and synepitheliochorial placentation. On average, does develop two CL after estrus [6, 7], which continuously produce P4 between July/August following ovulation and May/June the following year until fawning [8]. The plasma P4 concentrations did not show any changes from September to January, whereas it increased after attachment of fetal membranes. The latter was therefore suggested to be of placental origin [7-10]. These changes in peripheral P4 were not confirmed by others [11, 12]. Lambert (1999) found a fluctuation in luteal P4 from high during diapause, low during expansion and elongation, to high during implantation [13]. We recently reported that plasma P4, E2 and total estrogen concentrations remained constant between September and January, regardless of the different embryonic developmental stages, i.e., blastocysts, elongation and organogenesis [6]. Endometrial P4 and E2 concentrations were higher during diapause and elongation than during organogenesis [6]. Thus, we concluded that it is likely that these specific ovarian steroid hormones do not play a key role in resumption of embryonic growth [6].

Not only P4, but also its metabolites are biologically active and have been show to play a critical role during the estrus cycle and pregnancy [14-16]. P4 is can be enzymatically reduced at the C3-, C5- and C20-position [15]. The C3-

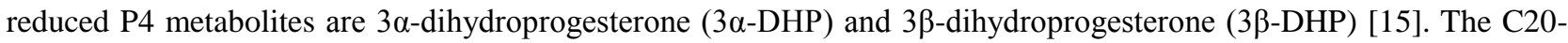
reduced metabolites include $20 \alpha$-dihydroprogesterone $(20 \alpha-\mathrm{DPH})$ and $20 \beta$-dihydroprogesterone (20 $\beta$-DHP) [15]. The C5-reduced metabolites include $5 \alpha$-dihydroprogesterone ( $5 \alpha$-DHP) and $5 \beta$-dihydroprogesterone (5 $\beta$-DHP) [15], which can be further metabolized to allopregnanolone ( $3 \alpha, 5 \alpha$-THP) and isopregnanolone ( $3 \beta, 5 \alpha-\mathrm{THP})$, and pregnanolone $(3 \alpha, 5 \beta-\mathrm{THP})$ and epipregnanolone $(3 \beta, 5 \beta-\mathrm{THP})$, respectively [15]. These P4 metabolites can bind the classical progesterone receptor (PR) or the GABAA-r, and thereby exert their effect on the estrus cycle and maintenance of pregnancy [14, 17, 18]. The PR has two isoforms, namely PR alpha and beta [19]. These isoforms selectively contribute to the cellular and molecular P4 actions [19]. In African and Asian elephants, P4 levels are 100 to 1000 -fold lower compared to other mammals [20]. Therefore, P4 was shown to not serve as functional progestogen. Postovulatory plasma $5 \alpha$-DHP was shown to increase to concentrations similar to P4 levels in other mammals [21]. In addition, PR binds $5 \alpha$-DHP and P4 with similar affinity [22]. Thus, $5 \alpha$-DHP is considered the functional progestogen in elephants. The relative binding affinity of the PR towards of 5C-reduced P4 metabolites, including both 5 $\alpha$-DHP and $5 \beta$-DHP, has been assessed in several species including horses, elephants, pigs and ruminants [18]. In horses and elephants, a relative binding affinity of 75-100\% and high blood concentrations of 5C-reduced metabolites were found [18]. Specifically in horses, P4 was undetectable in the second half of pregnancy and its function has been shown to be taken over by $5 \alpha$-DHP [14]. In pigs, the PR had an affinity of $50 \%$ to $5 \alpha$-DHP compared to P4, while in ruminants, the affinity of PR to $5 \alpha$-DHP was as low as $15 \%$ [18]. Thus, the P4 metabolite $5 \alpha$-DHP and its binding affinity to the PR display a species-specific function in pregnancy.

We aimed at quantifying the profile of the 11 progestogens in the roe deer plasma over the course of diapause and resumption of embryo development. We hypothesized a dynamic progestogen profile and aimed to shed light on the potential diapause regulatory role of $5 \alpha$-DHP.

\section{Materials and Methods}

The reproductive tract of 174 does was obtained during regular huntings from September 2018 to January 2019 [33]. No animals were specifically killed for the study. Therefore, ethical approval was not required. Blood was sampled by cardiac puncture and plasma was retrieved after centrifugation for 10 minutes at $1200 \times \mathrm{g}$ at $4^{\circ} \mathrm{C}$ of whole blood collected in hematology potassium EDTA tubes (Sarstedt, Germany). The plasma was snap frozen and stored at $-80^{\circ} \mathrm{C}$ until further analyses. The reproductive tract was collected after the animals were shot and kept on ice until further processing. The uterus was freed from residual connective tissue and flushed with $2.5 \mathrm{ml}$ phosphate buffered saline to recover the embryos. Embryos were visualized under a stereo microscope (Zeiss SteREO Discovery Microscope V8, 1:8 Zoom rate equipped with an Olympus SC50 camera). The diameter of each embryo was determined and after washing them in fresh PBS, the embryos were fixed in formalin for further analyses.

All progestogen standards were purchased from Steraloids Inc. (Newport, RI, USA). These included pregnenolone,

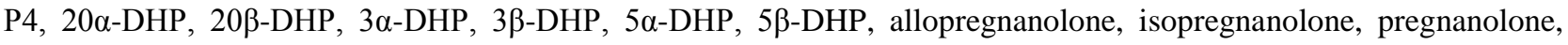
epipregnanolone, 5-pregnen-3 $\beta$-ol-20-one-17,21,21,21d4 (P5-d4) and 4-pregnen-3, 20-dione-2,2,4,6,6,17 $\alpha, 21,21,21$-d9 (P4-d9).

The procedure used for the extraction and quantification of progestogens is described elsewhere in details (Rehm et al., Simultaneous Quantification of Progestagens in Plasma and Serum by UHPLC-HRMS Employing Multiplexed 
Targeted Single Ion Monitoring, in preparation). Hankele et al., (2019), have described the quantification of the progestogens in plasma samples previously [15].

The progestogens were quantified in plasma samples of 89 pregnant does. Samples were selected based on the presence of at least one embryo and covered a high density with regard to sampling date and embryo developmental stage. Of each doe, $0.5 \mathrm{ml}$ plasma was spiked prior to extraction with P5-d4 and P4-d4 as internal standards (IS). The extraction was performed using solid phase extraction with a Strata-X $33 \mu \mathrm{m}$ polymeric reversed phase cartridge $(3 \mathrm{ml}$, $60 \mathrm{mg}$ sorbent) (Phenomenex Helvetia $\mathrm{GmbH}$, Basel, Switzerland). After the sample was loaded, the cartridge was washed with water (Milli-Q ${ }^{\circledR}$ Advantage A10 purification system, Merck, Bedford, MS, USA) and with 40\% acetonitrile $(\mathrm{ACN}) /$ methanol $(\mathrm{MeOH})(85: 15)$ in $\mathrm{H} 2 \mathrm{O}$. The steroids were eluted with a solution of $90 \% \mathrm{ACN} / \mathrm{MeOH}$ (85:15). The collected eluent was evaporated to dryness under nitrogen, and the residue was reconstituted in $50 \mu 1$ of $50 \%$ ACN with $0.1 \%$ formic acid (FA) and a volume of $5 \mu \mathrm{l}$ was injected into the LC-MS system.

Liquid chromatography was performed on an UltiMate 3000 UHPLC system from Thermo Fisher Scientific (Waltham, MA, USA). Compound separation was achieved on an Acquity UPLC HSS T3 column (100 $\AA, 1.8 \mu \mathrm{m}$, $2.1 \mathrm{~mm} \times 100 \mathrm{~mm}$, Waters, Milford, MA, USA) protected by the corresponding HSS T3 VanGuard pre-column (100 , $1.8 \mu \mathrm{m}, 2.1 \mathrm{~mm} \times 5 \mathrm{~mm}$ ). The mobile phase consisted of $\mathrm{H} 2 \mathrm{O}+0.1 \% \mathrm{FA}(\mathrm{A})$ and $\mathrm{ACN}+0.1 \% \mathrm{FA}(\mathrm{B})$. The flow rate was constant at $0.45 \mathrm{ml} / \mathrm{min}$. Elution was performed starting with isocratic conditions at $58 \% \mathrm{~B}$ during $0.5 \mathrm{~min}$, followed by a linear gradient 58-62\% B until $3.7 \mathrm{~min}$, then to $66 \% \mathrm{~B}$ until $6.0 \mathrm{~min}$, followed by a washing step with $100 \% \mathrm{~B}$ for $4 \mathrm{~min}$ and a re-equilibration at $58 \% \mathrm{~B}$ for $4 \mathrm{~min}$. The QExactive ${ }^{\mathrm{TM}}$ mass spectrometer was used for detection of the progestogens. The mass spectrometer was equipped with an ESI ion source (Thermo Fisher Scientific, Waltham, MA, USA), which was operated in positive ionization mode. Quantification was performed using the TraceFinder® software (Thermo Fisher Scientific, Waltham, MA, USA) in targeted single ion monitoring (tSIM) mode. The ratios of the analyte and IS peak area were plotted against concentration. The calibration curve for each progestogen was calculated using a quadratic regression with equal weighting, which was forced through the zeropoint. The calibration curves were prepared in charcoal stripped plasma ranging from $0.02 \mathrm{ng} / \mathrm{ml}$ to $20 \mathrm{ng} / \mathrm{ml}$ (calibration curve points: $0.02,0.05,0.1,0.2,0.5,1,5,10$ and $20 \mathrm{ng} / \mathrm{mL}$ ). Pregnenolone (P5) and $3 \beta$-DHP co-eluted and are therefore given as a sum. Both method accuracy and precision were determined at three different QC

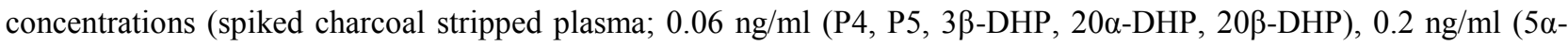

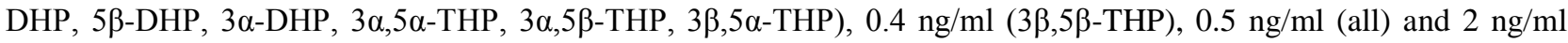
(all); each in duplicates during 4 different runs). The bias of the accuracy was $<15 \%$ for all analytes. The interday- and intraday precision was $<10 \%$ for $20 \alpha$-DHP, $20 \beta$-DHP, $3 \beta$-DHP, $5 \alpha$-DHP, $5 \beta$-DHP, $3 \beta, 5 \beta$-THP, P4 and P5, < $15 \%$ for $3 \beta, 5 \alpha$-THP and $<20 \%$ for $3 \alpha, 5 \beta$-THP and $3 \alpha$-DHP. Information on internal standards, monitored single ions, ion for quantification and limit of quantification are given in Table 1.

Table 1. Analyzed analytes with their respective internal standard, monitored single ions, ion for quantification and limit of quantification

\begin{tabular}{|c|c|c|c|c|}
\hline Analyte & Internal standard & Monitored single ion $[\mathrm{m} / \mathrm{z}]$ & Ion for quantification & Limit of quantification $[\mathrm{ng} / \mathrm{ml}]$ \\
\hline P4 & P4-d9 & 314.2246 & {$[\mathrm{M}+\mathrm{H}]+$} & 0.05 \\
\hline 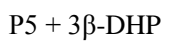 & P5-d4 & 316.2402 & {$[\mathrm{M}-\mathrm{H} 2 \mathrm{O}+\mathrm{H}]+$} & 0.05 \\
\hline $5 \beta$-DHP & P5-d4 & 316.2402 & {$[\mathrm{M}-\mathrm{H} 2 \mathrm{O}+\mathrm{H}]+$} & 0.2 \\
\hline $5 \alpha$-DHP & P5-d4 & 316.2402 & {$[\mathrm{M}+\mathrm{H}]+$} & 0.2 \\
\hline $3 \beta, 5 \beta-\mathrm{THP}$ & P5-d4 & 318.2559 & {$[\mathrm{M}+\mathrm{H}]+$} & 0.3 \\
\hline $3 \beta, 5 \alpha-\mathrm{THP}$ & P5-d4 & 318.2559 & {$[\mathrm{M}-\mathrm{H} 2 \mathrm{O}+\mathrm{H}]+$} & 0.1 \\
\hline $3 \alpha$-DHP & P5-d4 & 316.2402 & {$[\mathrm{M}-\mathrm{H} 2 \mathrm{O}+\mathrm{H}]+$} & 0.1 \\
\hline $3 \alpha, 5 \beta$-THP & P5-d4 & 318.2559 & {$[\mathrm{M}-\mathrm{H} 2 \mathrm{O}+\mathrm{H}]+$} & 0.1 \\
\hline $3 \alpha, 5 \alpha$-THP & P5-d4 & 318.2559 & {$[\mathrm{M}-\mathrm{H} 2 \mathrm{O}+\mathrm{H}]+$} & 0.1 \\
\hline 20ß-DHP & P4-d9 & 316.2402 & {$[\mathrm{M}+\mathrm{H}]+$} & 0.02 \\
\hline $20 \alpha-\mathrm{DHP}$ & P4-d9 & 316.2402 & {$[\mathrm{M}+\mathrm{H}]+$} & 0.02 \\
\hline
\end{tabular}

Luteal phase progestogen plasma data has previously been published by Hankele et al., (2019), and was used for a comparative analysis [15]. For the elephant serum progestogen data, blood samples were available from diagnostic purposes (own data not published). As an exemplary sample, a serum sample of day 35 prior to parturition was used to illustrate the progestogens during the late phase of pregnancy in the elephant. 
A metabolism analysis was conducted to gain insight into the species-specific progestogen profiles. For all species, relative concentrations of P4 were calculated with respect to the concentration in roe deer. Per species, the concentration of each P4 metabolite was plotted relative to P4. Roe deer data were used for a correlation analysis in R version 3.6.1 [34, 35]. A Pearson correlation was used and data is graphically displayed and ordered by hierarchical clustering. Only statistically significant correlations $(\mathrm{p}<0.05)$ are displayed in the correlation plot. The progestogen concentrations were plotted against the embryonic size to display the developmental-dependent changes. A LOESS regression, which allows local fitting with the weighted least squares method, was used in $\mathrm{R}$ version 3.6.1 [35].

\section{Results}

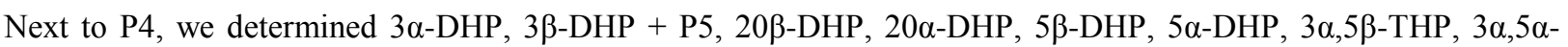
THP, $3 \beta, 5 \beta$-THP and $3 \beta, 5 \alpha$-THP in roe deer plasma over the course of diapause and reactivation. As comparison, plasma progestogens were determined in the cow during the luteal phase and in the elephant during late pregnancy

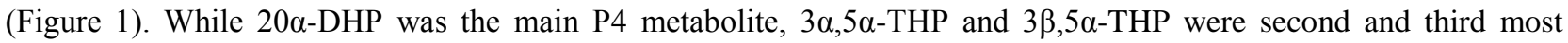
abundant in roe deer plasma (Figure 1). In cattle, $\mathrm{P} 4$ was the most abundant progestogen, followed by its metabolites $5 \alpha, 3 \alpha$-THP, $5 \alpha, 3 \beta$-THP and $5 \beta, 3 \beta$-THP [15]. Interestingly, in the elephant, the main progestogen was $5 \alpha$-DHP, followed by $3 \beta-\mathrm{DHP}+\mathrm{P} 5$ and $3 \alpha, 5 \alpha-\mathrm{THP}$.

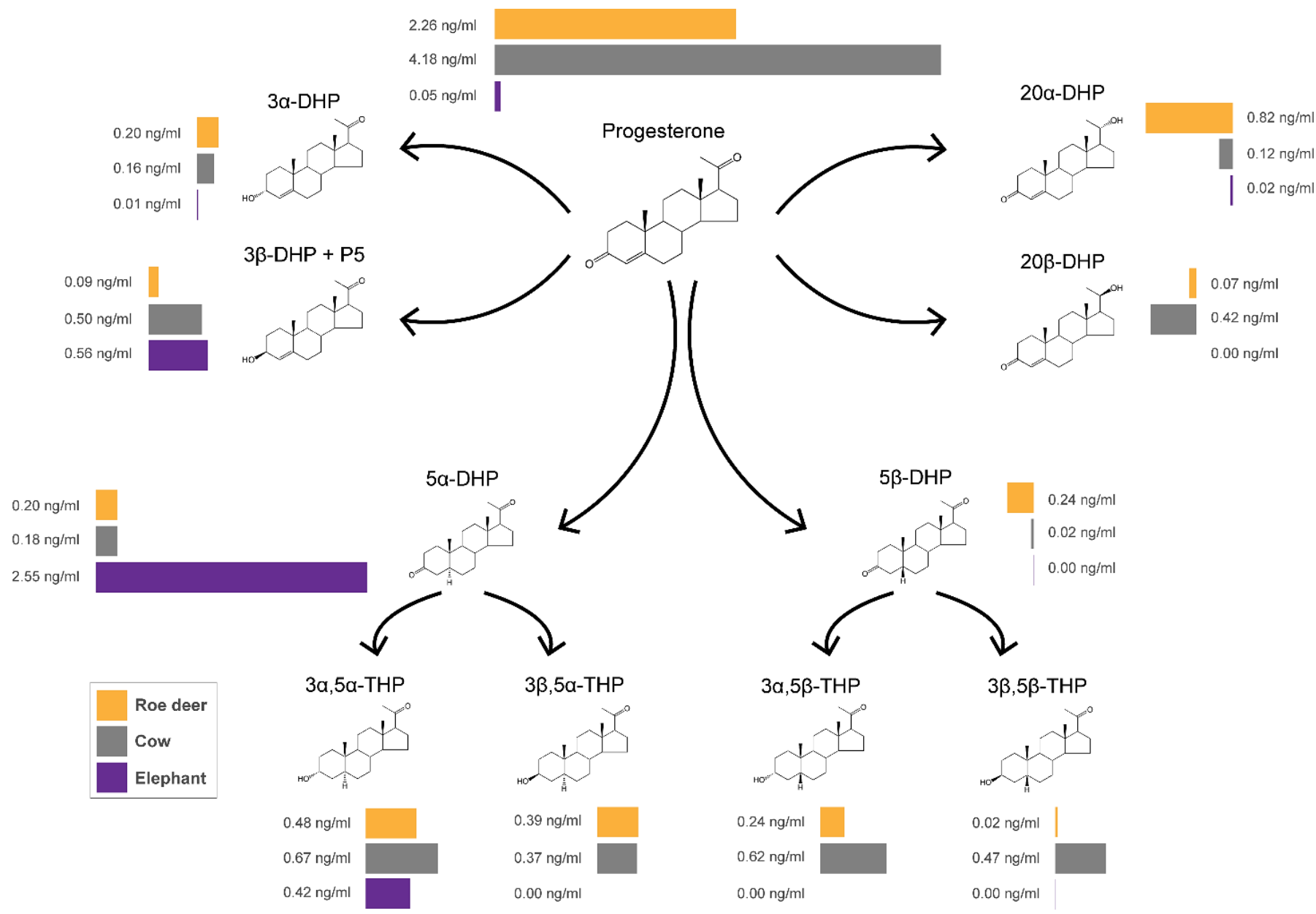

Figure 1. Plasma concentration of $\mathrm{P} 4$ and its metabolites. The concentration of each progestogen is indicated in $\mathrm{ng} / \mathrm{ml}$. The yellow, grey and purple bars represent the progestogen concentrations in the roe deer during diapause, the luteal phase in the cow [15], and late pregnancy in the elephant (unpublished own data)

The profiles of all progestogens, except $3 \beta, 5 \alpha$-THP, did not significantly change with developmental progression defined as either sampling date or embryo size (Figure 2 and Supplementary data I). There was a negative correlation between P4 and its metabolites 5 $\beta$-DHP, $3 \beta, 5 \beta$-THP and $3 \alpha, 5 \beta$-THP (Figure 2). 


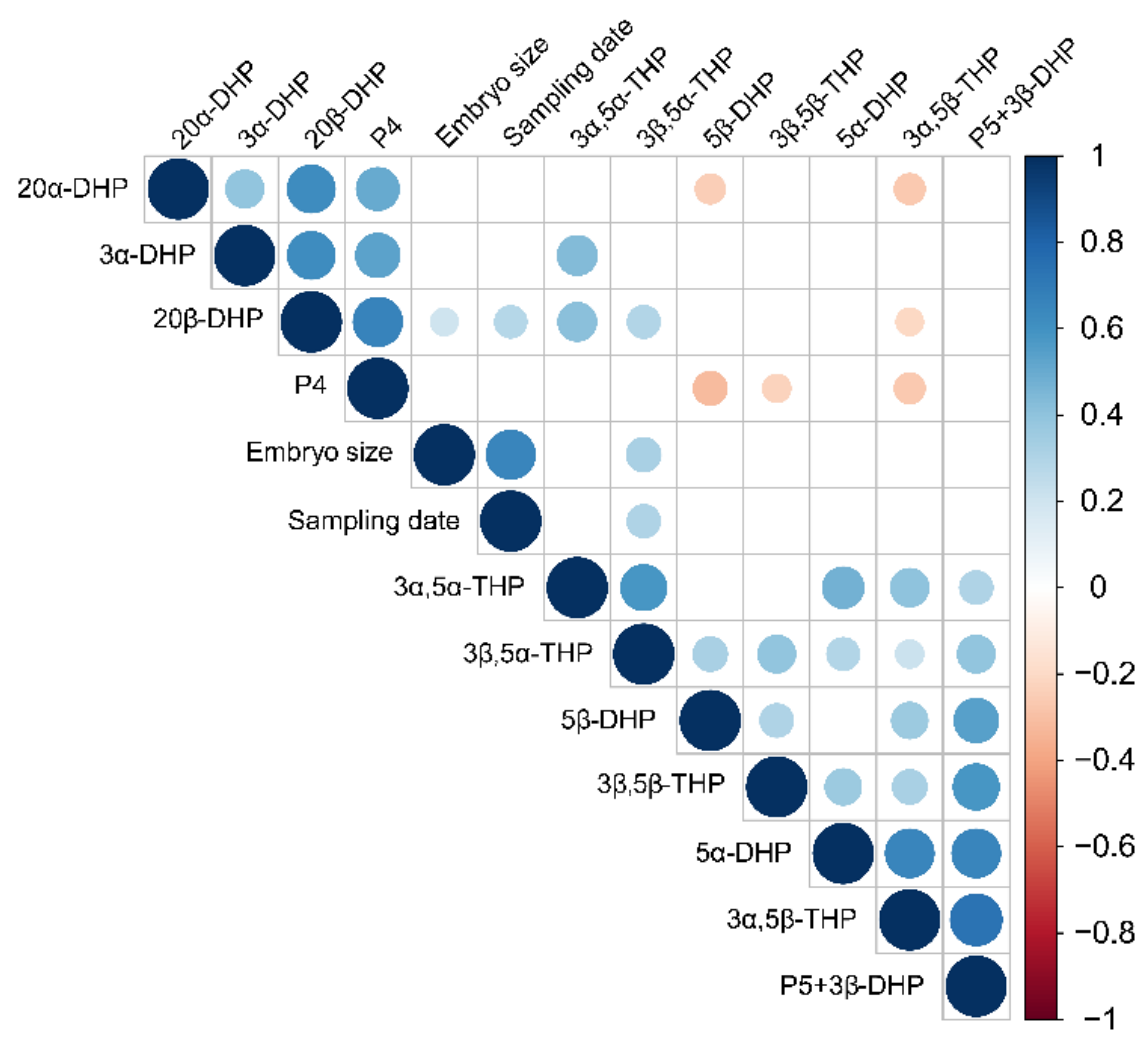

Figure 2. Pearson correlation plot with hierarchical clustering of the 11 progestogens, embryo size and sampling date. Significantly correlated variables $(p<0.05)$ are displayed and circle size and color indicate the degree of correlation (red and blue indicate a negative and positive correlation)

\section{Discussion}

To shed light on the potential diapause regulatory role of the progestogens, we profiled plasma $\mathrm{P} 4,3 \alpha$ - and $3 \beta$ -

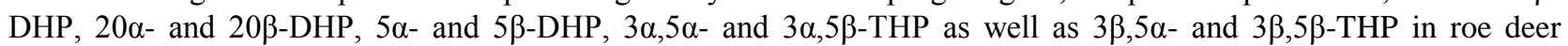
plasma over the course of diapause and reactivation. Using an enzyme-linked immunosorbent assay, we have previously shown that plasma and uterine tissue P4 concentrations did not change over time [6]. With the novel LCMS based approach and a new set of samples not previously analyzed, we did not find any changes of P4 over time. Plasma concentrations were 2-fold lower than previously reported, which is likely due to the limitation of antibodybased techniques, i.e., non-specific antigen binding of the antibody [16, 23]. None of the measured progestogens changed in concentrations with developmental progression.

P4 has been reported to be of importance for resumption of development in other diapausing species [24]. While in mice, P4 was shown to prime the uterus, in mink or tammar wallaby, P4 is necessary to stimulate the reactivation of the uterus [24]. Thus, the lack of change of the progestogens in roe deer indicates that they are likely not involved reactivation of embryo development. We have previously shown the loss of uterine PR with prolonged P4 exposure [25]. As the progestogens are present in significant amounts, they might play a role in priming the uterus like in mice. Embryo reactivation in mice is preceded by an E2 surge [24]. Endometrial tissue progestogen profiling should shed further light on the local function of progestogens in the priming of the uterus.

In roe deer, we determined $20 \alpha$-DHP as main P4 metabolite. In cattle and sheep, the PR binding capacity of $20 \alpha-$ DHP is approximately 6 times lower than of P4 [26, 27]. In the MCF-7 breast cancer cell line, 20 $\alpha$-DHP has previously been shown to have anti-aromatase properties [28]. The anti-aromatase properties of 20a-DHP would result in lower plasma E2 concentrations. However, plasma E2 concentrations are higher in roe deer plasma than in bovine plasma during pregnancy $[6,29]$. Thus, this does not follow the hypothesis that $20 \alpha$-DHP acts as anti-aromatase agent, as the abundance of $20 \alpha$-DHP is lower in cattle than in roe deer plasma [15]. In mice, the uterus converts E2 into catechol estrogens and thereby facilitates reactivation of the diapausing embryo [30]. Even though roe deer plasma E2 did not change, our results might hint towards a P4-primed uterus, where loss of the PR facilitates implantation, and catechol estrogen-induced reactivation of embryo development, as observed in mice [30].

Previous reports have shown species-specific abundances of progestogens and their affinity to the PR during the estrus cycle and pregnancy [18]. In pre-implantation roe deer plasma, the 5 $\alpha$-DHP concentration was comparable to the luteal phase in cattle, but was 13 times lower than during late pregnancy in the elephant [15]. Therefore, it is likely that the function of $5 \alpha$-DHP as main progestogen during pregnancy in elephants is not reflected in the roe deer. 
Interestingly, the 5 3 -DHP concentration was approximately one order of magnitude higher in roe deer than in cattle and the elephant, while its metabolites $3 \alpha, 5 \beta$-THP and $3 \beta, 5 \beta$-THP were higher in cattle than in roe deer [15]. The roe deer plasma concentration of $3 \beta, 5 \beta$-THP was comparable to the one in elephants. The progestogens $3 \alpha, 5 \alpha$-THP, $3 \beta, 5 \alpha$-THP, $3 \alpha, 5 \beta$-THP and 3 $3,5 \beta$-THP are classified as neurosteroids that bind the GABAA-r in the brain [31]. In the brain of pregnant rats, the plasticity of these receptors is related to fluctuations of endogenous brain progestogen concentrations, and the concentrations have been shown to be different then in the plasma [32]. The precise role of these neurosteroids in pregnancy is yet to be determined.

\section{Conclusion}

In conclusion, we show that plasma progestogen concentrations did not change with developmental progression. We identified 20 $\alpha$-DHP as most abundant P4 metabolite and could not show the contribution of $5 \alpha$-DHP to preimplantation embryo development. We propose that progestogens play a role in priming the uterus for reactivation of embryo development and thereby support successful implantation after embryonic diapause.

\section{Funding}

This study was funded by the Swiss National Science Foundation SNSF (31003A_159734 and 310030_185026).

\section{Acknowledgements}

We thank and appreciate the local hunters in Switzerland and Southern Germany for their continued help in sample collection. We specifically acknowledge Florian Moser and Imme Rutzen for the sample collection. We thank Dr. M. Kummrow, Zoo Hanover, Germany, for the elephant samples. The authors are active participants of the COST Action CA16119 (CellFit - In vitro 3D total cell guidance and fitness).

\section{Declaration of Competing Interest}

The authors declare that they have no known competing financial interests or personal relationships that could have appeared to influence the work reported in this paper.

\section{Ethical Approval}

All procedures performed in studies involving human participants were in accordance with the ethical standards of the institutional and/or national research committee and with the 1964 Helsinki declaration and its later amendments or comparable ethical standards.

\section{References}

[1] Noguchi, M., Yoshioka, K., Itoh, S., Suzuki, C., Arai, S., Wada, Y., . . Kaneko, H. (2010). Peripheral concentrations of inhibin A, ovarian steroids, and gonadotropins associated with follicular development throughout the estrous cycle of the sow. Reproduction, 139(1), 153-161. doi:10.1530/rep-09-0018.

[2] Soede, N. M., Langendijk, P., \& Kemp, B. (2011). Reproductive cycles in pigs. Anim Reprod Sci, 124(3-4), 251-258. doi:10.1016/j.anireprosci.2011.02.025.

[3] Forde, N., Beltman, M. E., Lonergan, P., Diskin, M., Roche, J. F., \& Crowe, M. A. (2011). Oestrous cycles in Bos taurus cattle. Animal Reproduction Science, 124(3-4), 163-169. doi:10.1016/j.anireprosci.2010.08.025.

[4] Bischoff, T. L. W. (1854). Die Entwicklungsgeschichte des Rehes: Giessen, J. Bicker'sche Buchhandlung.

[5] Keibel, F. (1902). Die Entwicklung des Rehes bis zur Anlage des Mesoblast. . Anat. Physiol. Suppl. 292.

[6] Drews, B., Rudolf Vegas, A., van der Weijden, V. A., Milojevic, V., Hankele, A. K., Schuler, G., \& Ulbrich, S. E. (2019). Do ovarian steroid hormones control the resumption of embryonic growth following the period of diapause in roe deer (Capreolus capreolus)? Reprod Biol. doi:10.1016/j.repbio.2019.04.003.

[7] Sempere, A. J., Mauget, R., \& Chemineau, P. (1992). Experimental induction of luteal cyclicity in roe deer (Capreolus capreolus). Reproduction, 96(1), 379-384. doi:10.1530/jrf.0.0960379.

[8] Hoffmann, B., Barth, D., \& Karg, H. (1978). Progesterone and Estrogen Levels in Peripheral Plasma of the Pregnant and Nonpregnant Roe Deer (Capreolus capreolus). Biology of Reproduction, 19(5), 931-935. doi:10.1095/biolreprod19.5.931.

[9] Short, R. V., \& Hay, M. F. (1966). Delayed Implantation in the roe deer Capreolus capreolus. In I. W. Rowlands (Ed.), Comparative Biology of Reproduction in Mammals (pp. 173-194). New York: Academic Press. 
[10] Sempere, A. J., Renaud, G., \& Bariteau, F. (1989). Embryonic development measured by ultrasonography and plasma progesterone concentrations in roe deer (Capreolus capreolus L.). Animal Reproduction Science, 20(2), $155-164$. doi:10.1016/0378-4320(89)90072-9.

[11] Lambert, R., Ashworth, C., Beattie, L., Gebbie, F., Hutchinson, J., Kyle, D., \& Racey, P. (2001). Temporal changes in reproductive hormones and conceptus-endometrial interactions during embryonic diapause and reactivation of the blastocyst in European roe deer (Capreolus capreolus). Reproduction, 863-871. doi:10.1530/rep.0.1210863

[12] Schams, D., Barth, D., \& Karg, H. (1980). LH, FSH and progesterone concentrations in peripheral plasma of the female roe deer (Capreolus capreolus) during the rutting season. Reproduction, 60(1), 109-114. doi:10.1530/jrf.0.0600109.

[13] Lambert, R. T. (1999). Conceptus-endometrial interactions and reproductive hormone profiles during embryonic diapause and reactivation of the blastocyst in the European roe deer (Capreolus capreolus). Rangifer, 19(1), 41. doi:10.7557/2.19.1.294.

[14] Scholtz, E. L., Krishnan, S., Ball, B. A., Corbin, C. J., Moeller, B. C., Stanley, S. D., ... Conley, A. J. (2014). Pregnancy without progesterone in horses defines a second endogenous biopotent progesterone receptor agonist, $5 \alpha$-dihydroprogesterone. Proceedings of the National Academy of Sciences, 111(9), 3365-3370. doi:10.1073/pnas.1318163111.

[15] Hankele, A. K., Rehm, K., Berard, J., Schuler, G., Bigler, L., \& Ulbrich, S. E. (2020). Progestogen profiling in plasma during the estrous cycle in cattle using an LC-MS based approach. Theriogenology, 142, $376-383$. doi:10.1016/j.theriogenology.2019.10.005.

[16] Schwarzenberger, F., Son, C. H., Pretting, R., \& Arbeiter, K. (1996). Use of group-specific antibodies to detect fecal progesterone metabolites during the estrous cycle of cows. Theriogenology, 46(1), 23-32. doi:10.1016/0093-691x(96)00138-0.

[17] Skinner, D. C., Evans, N. P., Delaleu, B., Goodman, R. L., Bouchard, P., \& Caraty, A. (1998). The negative feedback actions of progesterone on gonadotropinreleasing hormone secretion are transduced by the classical progesterone receptor. Proceedings of the National Academy of Sciences, 95(18), 10978-10983. doi:10.1073/pnas.95.18.10978.

[18] Jewgenow, K., \& Meyer, H. H. D. (1998). Comparative Binding Affinity Study of Progestins to the Cytosol Progestin Receptor of Endometrium in Different Mammals. General and Comparative Endocrinology, 110(2), 118-124. doi:10.1006/gcen.1997.7054.

[19] Mulac-Jericevic, B., \& Conneely, O. M. (2004). Reproductive tissue selective actions of progesterone receptors. Reproduction, 128(2), 139-146. doi:10.1530/rep.1.00189.

[20] Meyer, H. H., Jewgenow, K., \& Hodges, J. K. (1997). Binding activity of 5alpha-reduced gestagens to the progestin receptor from African elephant (Loxodonta africana). Gen Comp Endocrinol, 105(2), 164-167. doi:10.1006/gcen.1996.6813.

[21] Hodges, J. K. (1998). Endocrinology of the ovarian cycle and pregnancy in the Asian (Elephas maximus) and African (Loxodonta africana) elephant. Anim Reprod Sci, 53(1-4), 3-18. doi:10.1016/s0378-4320(98)00123-7.

[22] Wierer, M., Schrey, A. K., Kühne, R., Ulbrich, S. E., \& Meyer, H. H. D. (2012). A Single Glycine-Alanine Exchange Directs Ligand Specificity of the Elephant Progestin Receptor. PLoS One, 7(11), e50350. doi:10.1371/journal.pone.0050350.

[23] Schwarzenberger, F., Mostl, E., Bamberg, E., Pammer, J., \& Schmehlik, O. (1991). Concentrations of progestagens and oestrogens in the faeces of pregnant Lipizzan, trotter and thoroughbred mares. J Reprod Fertil Suppl, 44, 489-499.

[24] Renfree, M. B., \& Fenelon, J. C. (2017). The enigma of embryonic diapause. Development, 144(18), 3199-3210. doi:10.1242/dev.148213.

[25] Van der Weijden, V. A., Puntar, B., Rudolf Vegas, A., Milojevic, V., Schanzenbach, C. I., Kowalewski, M. P., ... Ulbrich, S. E. (2019). Endometrial luminal epithelial cells sense embryo elongation in the roe deer independent of interferon-tau. Biology of Reproduction. doi:10.1093/biolre/ioz129.

[26] Vacas, M. I., Lowenstein, P. R., \& Cardinali, D. P. (1979). Characterization of a cytosol progesterone receptor in bovine pineal gland. Neuroendocrinology, 29(2), 84-89. doi:10.1159/000122909.

[27] Ashley, R. L., Arreguin-Arevalo, J. A., \& Nett, T. M. (2009). Binding characteristics of the ovine membrane progesterone receptor alpha and expression of the receptor during the estrous cycle. Reproductive Biology and Endocrinology, 7(1), 42. doi:10.1186/1477-7827-7-42.

[28] Pasqualini, J. R., \& Chetrite, G. (2008). The anti-aromatase effect of progesterone and of its natural metabolites 20alpha- and 5alpha-dihydroprogesterone in the MCF-7aro breast cancer cell line. Anticancer Res, 28(4b), 2129-2133.

[29] Pape-Zambito, D. A., Magliaro, A. L., \& Kensinger, R. S. (2008). 17 $\beta$-Estradiol and Estrone Concentrations in Plasma and Milk During Bovine Pregnancy. Journal of Dairy Science, 91(1), 127-135. doi:10.3168/jds.2007-0481.

[30] Hoversland, R. C., Dey, S. K., \& Johnson, D. C. (1982). Catechol estradiol induced implantation in the mouse. Life Sci, 30(21), 1801-1804. doi:10.1016/0024-3205(82)90316-2. 
[31] Stromberg, J., Haage, D., Taube, M., Backstrom, T., \& Lundgren, P. (2006). Neurosteroid modulation of allopregnanolone and GABA effect on the GABA-A receptor. Neuroscience, 143(1), 73-81. doi:10.1016/j.neuroscience.2006.07.031.

[32] Concas, A., Mostallino, M. C., Porcu, P., Follesa, P., Barbaccia, M. L., Trabucchi, M., . . Biggio, G. (1998). Role of brain allopregnanolone in the plasticity of gamma-aminobutyric acid type A receptor in rat brain during pregnancy and after delivery. Proc Natl Acad Sci U S A, 95(22), 13284-13289. doi:10.1073/pnas.95.22.13284.

[33] Rüegg, A. B., Bernal-Ulloa, S. M., Moser, F., Rutzen, I., \& Ulbrich, S. E. (2019). Trophectoderm and Embryoblast of the European Roe Deer (Capreolus capreolus) both proliferate at slow pace during Embryonic Diapause (Submitted).

[34] Friendly, M. (2002). Corrgrams. The American Statistician, 56(4), 316-324. doi:10.1198/000313002533.

[35] Wickham, H. (2016). ggplot2: Elegant Graphics for Data Analysis: Springer-Verlag New York. 


\section{Supplementary Data I}

LOESS fit of the progestogens against embryonic size as proxy for developmental stage.
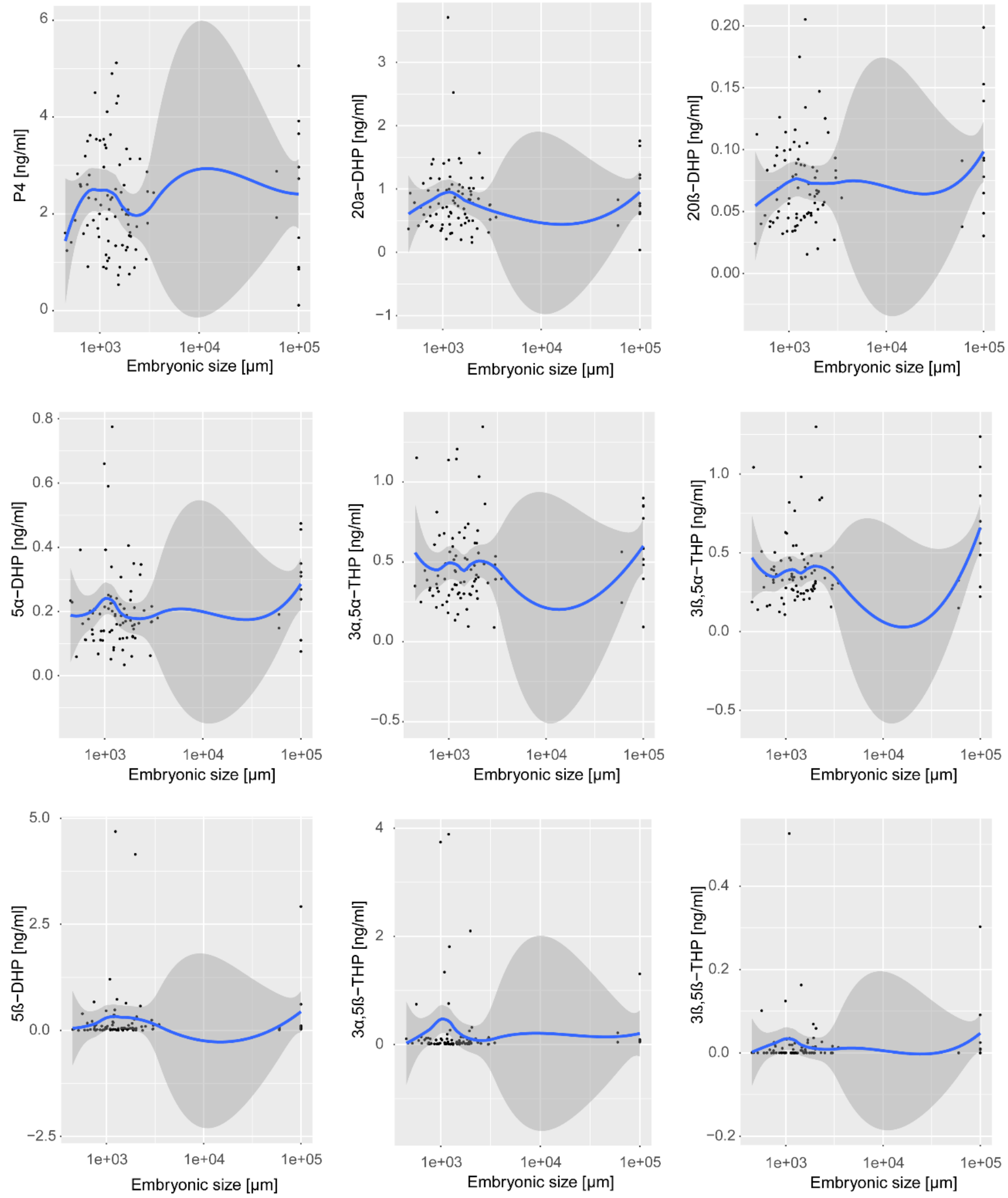

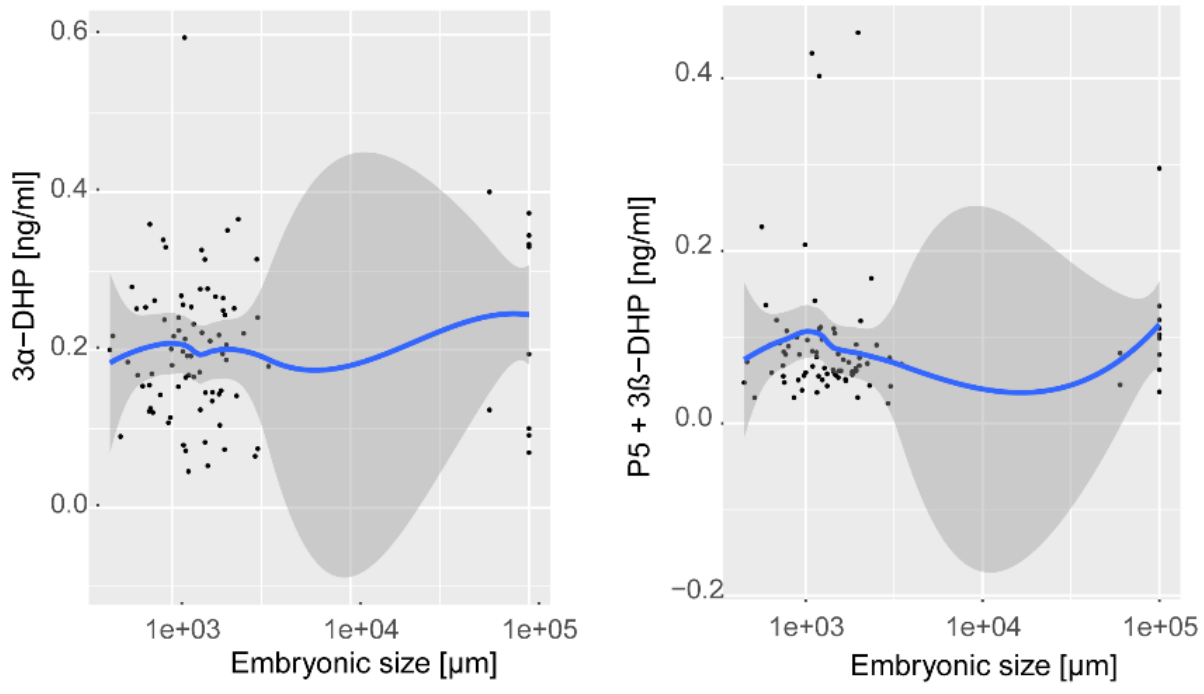